\title{
Perancangan Controlling System Keamanan Berbasis Arduino Menggunakan Kamera Internet Protocol
}

\author{
Ridwan $^{1 *}$, Asmaul Husna ${ }^{2}$ \\ ${ }^{1}$ Pendidikan Teknik Elektro, Fakultas Tarbiyah dan Keguruan, UIN Ar-raniry, Banda Aceh \\ ${ }^{2}$ Teknik Informatika, Fakultas Teknik, Universitas Jabal Ghafur, Sigli \\ *Koresponden email: ridwanmt @ar-raniry.ac.id
}

Diterima: 23 Desember 2019

Disetujui: 28 Januari 2020

\begin{abstract}
The act of theft is an act carried out without being known by the owner. It takes vigilance in maintaining security at home, shops, buildings and other places. This study discusses how to design a room security system equipped with sensors placed at the entrance or at other locations that are equipped with security system applications. The study used ultrasonic sensors mounted on the door of the room and the Arduino microcontroller as a tool to process and the buzzer that functions to issue a warning sound. Cameras IP used to display indoor images and website applications to display and control streaming. The application works to detect when there is a movement approaching at a certain distance to the sensor. When there is a movement, the sensor will send a signal to Arduino and then Arduino sends a notification to the user. Users receive phone call notifications and can view room conditions through camera access on the website application. Website application is equipped with a control menu display that functions to turn on and off the alarm. The system prototype can send notifications to users via mobile phones if there is movement in a room with an IP camera.
\end{abstract}

Keywords: security rooms system, Arduino, warning notifications, IP cameras, ultrasonic sensors

\begin{abstract}
Abstrak
Aksi pencurian merupakan perbuatan yang dilakukan tanpa diketahui oleh pemiliknya. Dibutuhkan kewaspadaan dalam menjaga keamanan di rumah, pertokoan, gedung dan tempat lainnya. Penelitian ini membahas bagaimana merancang sistem keamanan ruangan yang dilengkapi sensor yang diletakkan pada pintu masuk atau pada lokasi lainnya yang dilengkapi dengan aplikasi sistem keamanan. Penelitian menggunakan sensor ultrasonik yang dipasang pada pintu ruangan dan mikrokontroller arduino sebagai alat untuk memproses serta buzzer yang berfungsi untuk mengeluarkan bunyi peringatan. Kamera IP digunakan untuk menampilkan gambar keadaan dalam ruangan dan aplikasi website untuk menampilkan dan mengontrol streaming. Aplikasi bekerja untuk mendeteksi ketika ada suatu gerakan yang mendekat pada jarak tertentu terhadap sensor. Ketika terjadi suatu gerakan, sensor akan mengirimkan sinyal pada arduino dan selanjutnya arduino mengirimkan notifikasi kepada user. User menerima notifikasi panggilan telepon dan dapat melihat kondisi ruangan melalui akses kamera pada aplikasi website. Aplikasi website dilengkapi dengan tampilan menu kontrol yang berfungsi untuk menyalakan dan mematikan alarm. Prototipe sistem dapat mengirimkan notifikasi kepada pengguna melalui handphone apabila terdapat gerakan dalam ruangan yang dipasangi kamera IP.
\end{abstract}

Kata Kunci: Sistem keamanan ruangan, arduino, notifikasi peringatan, kamera IP, sensor ultrasonik

\section{Pendahuluan}

Pengamanan rumah atau Gedung banyak yang menggunakan kamera Closed Circuit Television (CCTV). Penggunaan CCTV membutuhkan beragam kabel untuk menghubungkan kamera dengan decoder/Digital Video Recording (DVR) dan terkadang dapat mengganggu tata letak tempat pemasangan. Kamera CCTV menggunakan kabel coaxial dengan teknologi analog dan konvensional, hal ini menyebabkan proses instalasi yang relative mahal [1]. Kekurangan lain penggunaan CCTV untuk pengamanan yaitu tidak dapat mengirimkan pemberitahuan (notifikasi) kepada pengguna atau real time, sehingga pengontrolan keamanan hanya dapat dilakukan ketika pengguna membuka aplikasi CCTV [2].

Penelitian ini bertujuan untuk menganalisis hubungan antara perangkat Arduino, sensor dan kamera Internet Protocol (IP) serta mengimplementasikan proses kerja dalam merancang controling system kamera IP secara realtime untuk mempermudah dalam upaya pencegahan dan keamanan suatu ruangan. 
Sistem yang dirancang menggabungkan mikrokontroller arduino dengan sensor yang tersambung dengan kamera IP yang bertujuan mendeteksi hal-hal mencurigakan pada suatu ruangan. Sistem juga mampu di kontrol dengan perangkat smartphone atau komputer sehingga user dapat memantau keadaan secara realtime. Kamera IP merupakan pilihan untuk kombinasi antara jaringan internet dan Internet Protocol Camera (IP Camera) yang dapat menghasilkan sebuah kamera pemantau sederhana yang dapat diakses secara langsung melalui internet.

Kamera IP dapat berfungsi sebagai sensor gerak, dimana kamera akan mulai merekam pada saat terdeteksi gerakan dari suatu objek dan akan memberikan peringatan dini [3]. Kamera tersebut dihubungkan dengan komputer server yang berfungsi menyimpan semua history hasil rekaman dari pemantauan kamera. Pada saat pengguna ingin melihat semua history pemantauan, bahkan melakukan pengaturan terhadap kamera yang ada dapat langsung melalui aplikasi website yang telah dirancang untuk antarmuka dari pengguna dengan kamera pemantau tanpa perlu mengakses langsung melalui kamera. Peringatan akan diberikan jika ada yang mendekat dalam jarak tertentu sesuai dengan perintah yang diupload ke dalam alat, notifikasi berupa alat akan melakukan panggilan kepada user. Pengguna dapat mengakses aplikasi website untuk melakukan pengontrolan dan mengaktifkan alarm sebagai peringatan dan pencegahan apabila melihat suatu gerakan yang mencurigakan.

Penelitian tentang keamanan berbasis Arduino dan kamera IP telah dilakukan oleh Satriawaty Mallu [1]. Dalam penelitiannya menghasilkan sistem keamanan yang dapat mendeteksi gerakan dan aplikasi dapat menyimpan gambar, menyimpan video dan dapat mengirimkan peringatan kepada pengguna dalam bentuk short message services (SMS). Penelitian lainnya juga dilakukan Hafidh As Syahidulhaq [4]. Penelitian ini menggunakan sensor Passive Infrared Reciever (PIR) dan SMS gateway untuk mengirimkan pemberitahuan kepada pengguna.

\section{Metode Penelitian}

Metode yang digunakan pada penelitian ini meliputi studi literatur, analisis, perancangan, implementasi dan evaluasi.

\section{a. Studi literatur}

Studi literatur meliputi studi pustaka pada jurnal, buku dan artikel online sebagai dasar untuk merancang aplikasi dan kebutuhan alat.

\section{b. Analisis}

Tahap analisis dilakukan untuk melihat kekurangan dari sistem berjalan.

\section{c. Perancangan}

Merancang aplikasi pengontrol keamanan ruang menggunakan kamera IP berbasis arduino yang akan dikoneksikan dengan sensor dan terkoneksi dengan aplikasi website.

\section{d. Implementasi}

Melakukan uji coba sistem secara keseluruhan dalam menjalankan program serta mengkoneksikan hardware ke software maupun sebaliknya.

\section{e. Evaluasi}

Tahap evaluasi bertujuan untuk pengumpulan kesalahan yang terjadi pada aplikasi.

Rangkaian sistem yang digunakan dalam bentuk diagram blok yang ditunjukkan pada Gambar 1. Cara kerja sistem yaitu ketika ada sesuatu yang mendekat pada jarak tertentu terhadap sensor, maka sensor akan mengirimkan sinyal terhadap Arduino, lalu Arduino mengirimkan notifikasi berupa panggilan kepada user sebagai bentuk adanya deteksi gerakan. Sisi lain user akan menerima notifikasi berupa panggilan telepon dan melihat kondisi area pengawasan melalui akses kamera pada website. Sistem dilengkapi dengan menu kontrol alarm untuk menyalakan dan mematikan alarm melalui website sebagai peringatan dan pencegahan awal. 


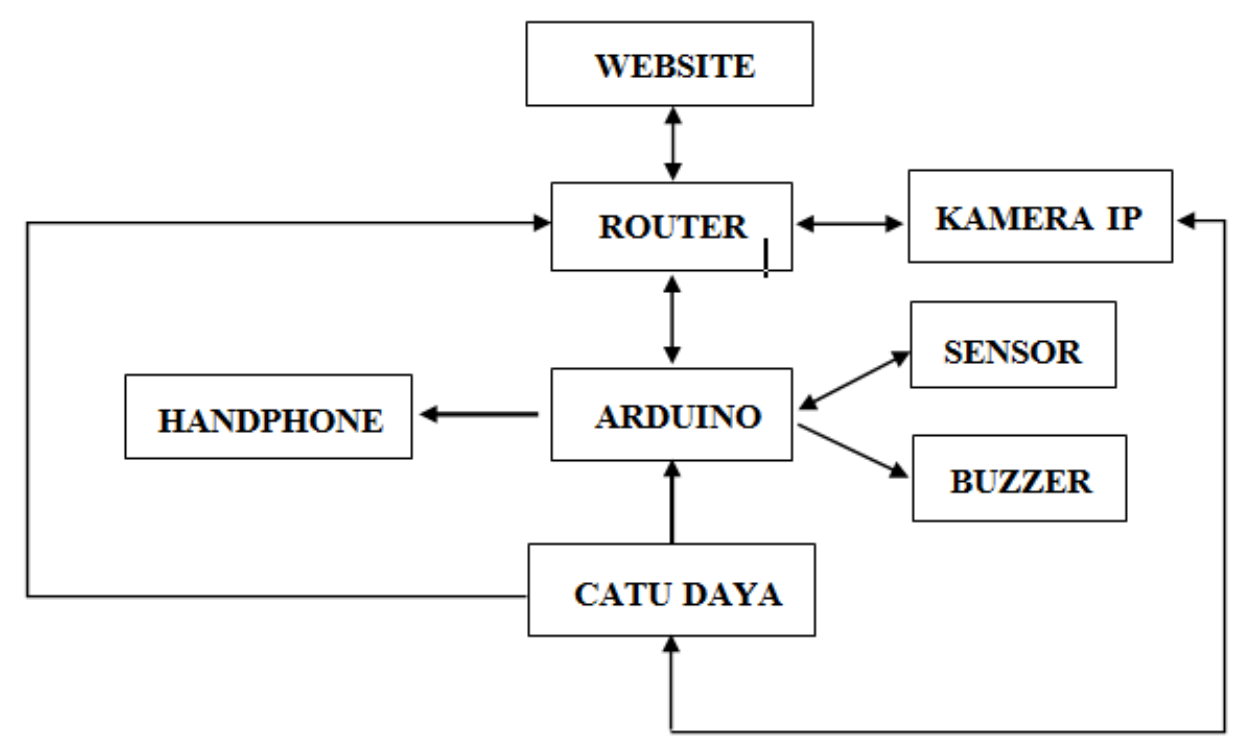

Gambar 1. Diagram blok rangkaian

Rangkaian pembentuk controlling system keamanan ruangan ini terdiri dari beberapa sistem kecil yang nantinya dihubungkan menjadi satu kesatuan sistem, sebagaimana Gambar 2.

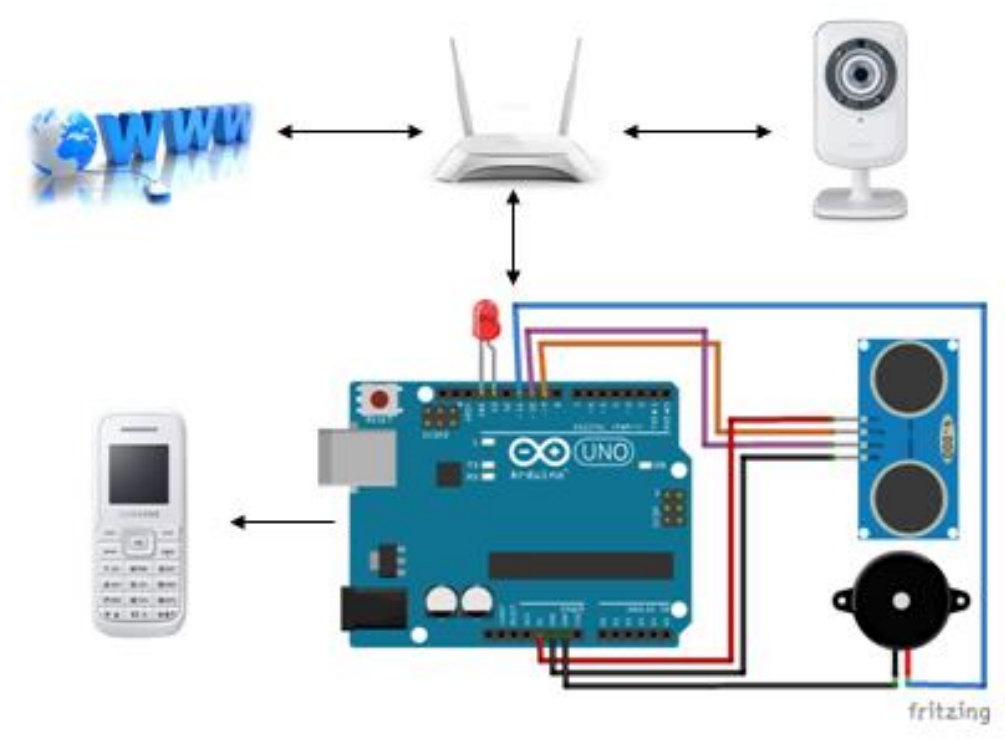

Gambar 2. Cara kerja sistem

Rancangan flowchart seperti yang ditunjukkan Gambar 3, awalnya sensor mengindentifikasi gerakan pada sistem kamera pengawas. Pada saat sensor mendeteksi adanya gerakan maka sinyal gerakan tersebut akan dikirimkan ke arduino. Jika tidak ada gerakan, maka kembali lagi ke proses sebelumnya (sensor kembali mendeteksi gerakan). Arduino memproses sinyal gerakan menjadi sebuah notifikasi berupa panggilan telepon. Pada pengguna akan menerima notifikasi dan login pada website dengan mengisi data berupa username dan password untuk dapat terhubung ke sistem. Selanjutnya sistem akan memeriksa apakah yang melakukan login adalah user, apabila benar, maka pengguna akan dapat mengakses kamera dan mendapatkan streaming dari kamera tersebut apabila salah, sebuah pesan kesalahan akan muncul dan mengarahkan pengguna untuk kembali melakukan login. Terakhir, pengguna dapat memutuskan kendali kontrol alarm untuk pesan peringatan dengan tujuan pencegahan awal. 


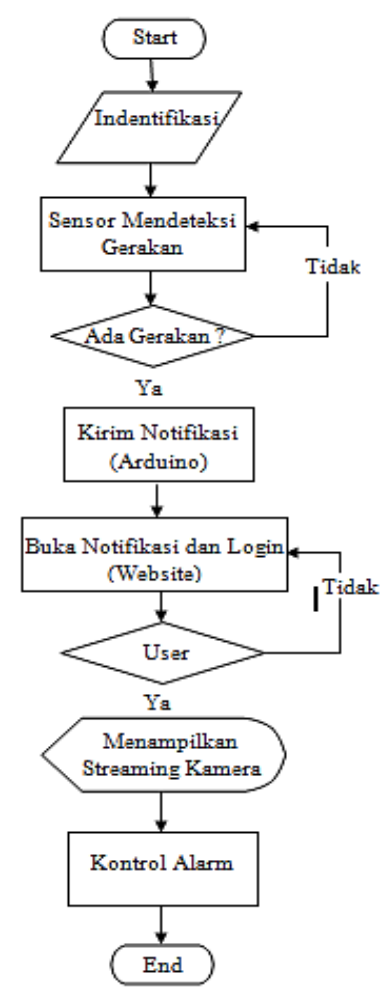

Gambar 3. Flowchart sistem

Gambar 4 merupakan rancangan form yang berfungsi untuk menampilkan streaming dan kontrol kamera serta alarm. Pada form ini terdapat fitur zoom camera berguna untuk memperbesar atau memperkecil suatu objek yang terekam oleh kamera, tombol $\mathrm{x} 1$ sampai $\mathrm{x} 4$. Fitur audio camera berguna untuk mengontrol audio yang terekam oleh kamera, tombol on dan off. Fitur alarm berguna untuk mengontrol alarm, tombol on dan off serta exit untuk keluar dari aplikasi.

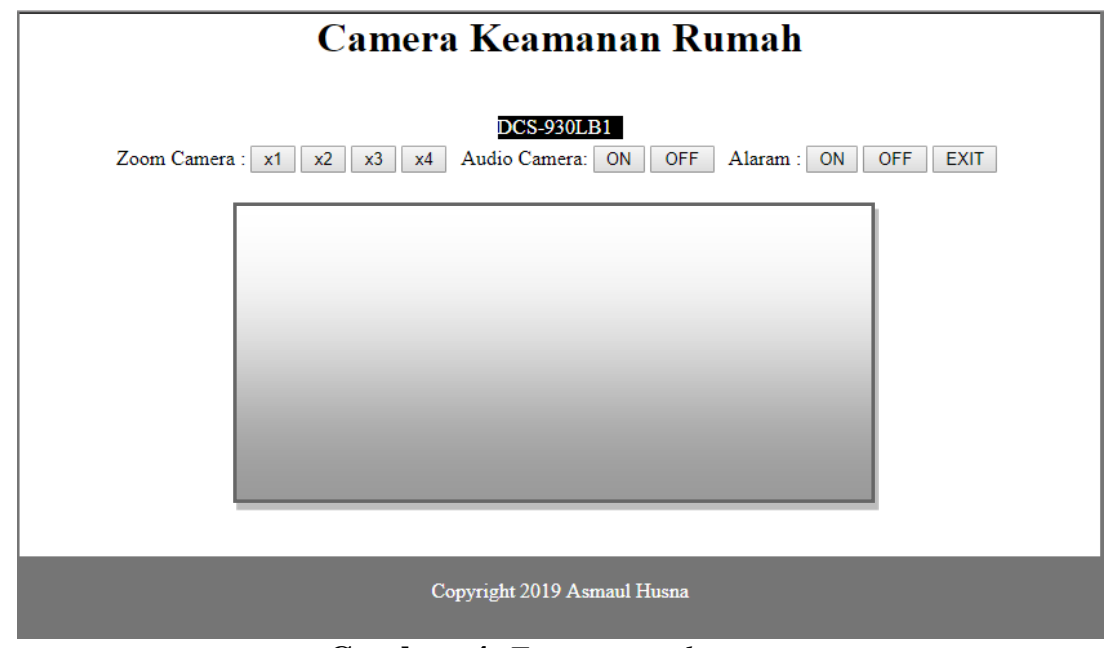

Gambar 4. Form control system

Sumber: Gambar pribadi

\section{Hasil dan Pembahasan}

Hasil penelitian berupa sebuah rangkaian prototipe controlling system keamanan ruangan seperti yang terlihat pada Gambar 5. Perangkat yang sudah dirakit yang terdiri dari Arduino uno, sensor ultrasonic, buzzer, GSM SIM900, ethernet shield, relay, kabel LAN, kamera IP, router, dan komponen tambahan lainnya. 


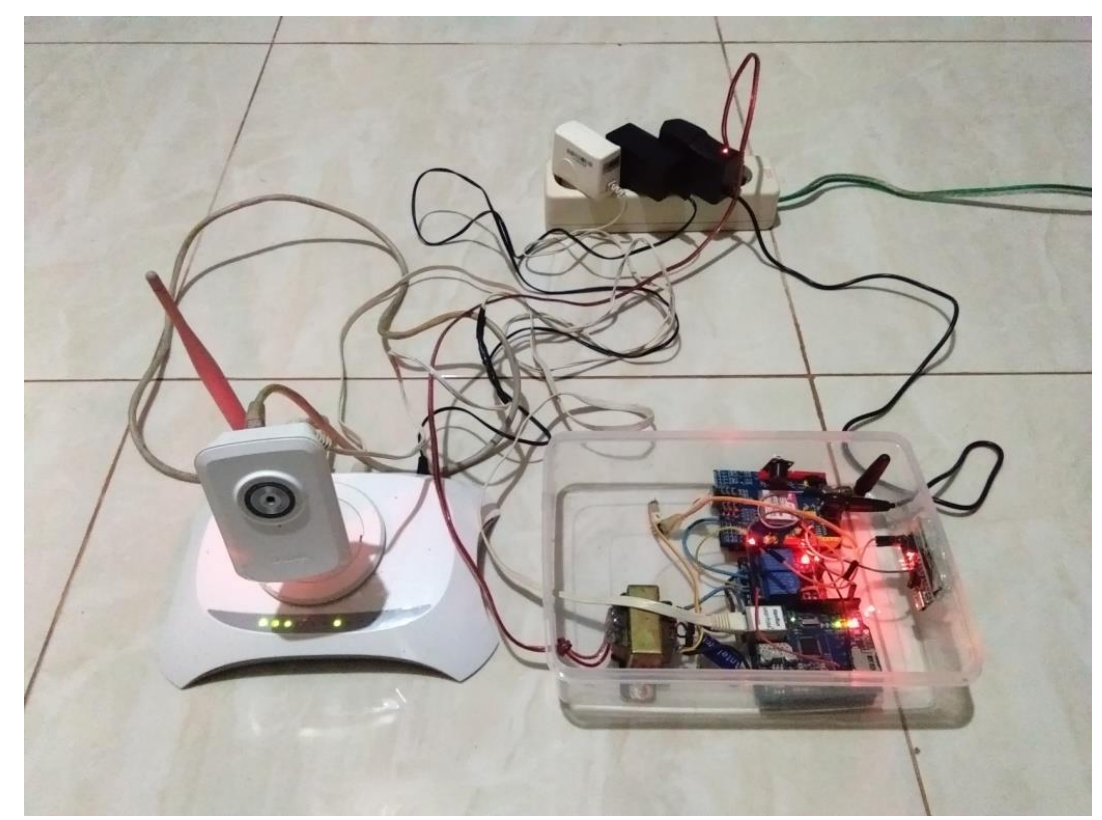

Gambar 5. Hasil uji sistem Sumber: Gambar pribadi

Halaman login aplikasi website menampilkan inputan berupa username dan password seperti tampak pada Gambar 6. User akan beralih ke halaman controlling system atau halaman utama aplikasi apabila berhasil melakukan login.

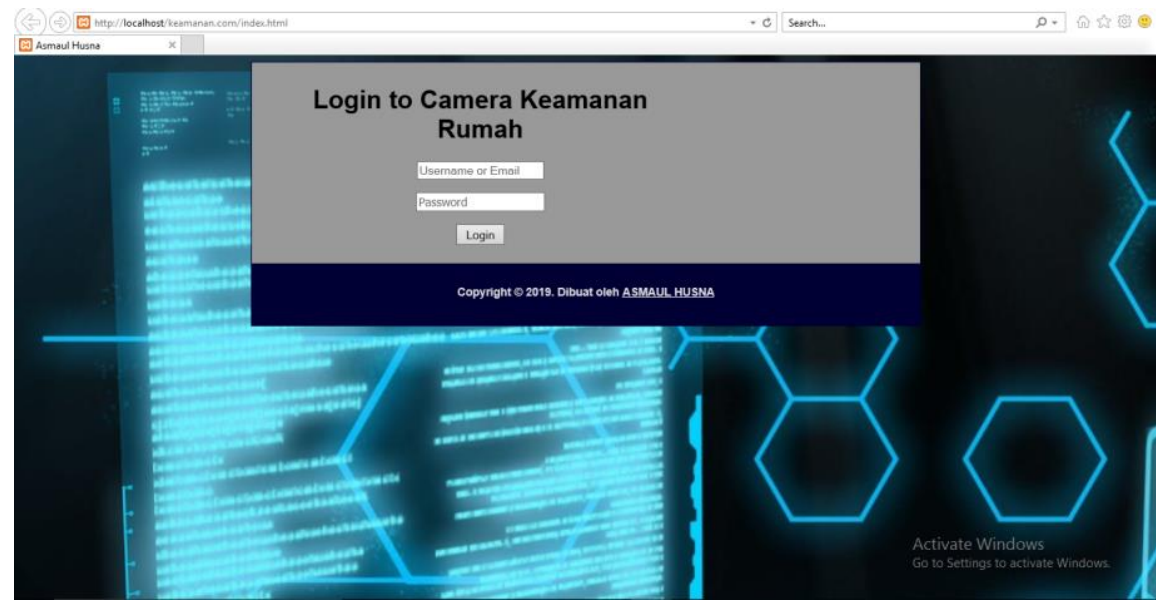

Gambar 6. Login pada aplikasi website

Sumber: Gambar pribadi

Setelah perangkat dihidupkan, alarm akan hidup otomatis. Pengguna dapat menghidupkan dan mematikan alarm, melihat keadaan ruangan, audio kamera dan zoom kamera pada halaman utama controlling seperti tampak pada Gambar 7. Tombol refresh pada GSM SIM 900 bertujuan supaya GSM SIM900 dalam keadaan standby untuk melakukan panggilan telepon. Ketika sensor ultrasonic terhalang dalam jarak maksimal $30 \mathrm{~cm}$ maka GSM SIM900 akan melakukan telepon dan disisi lain alarm berbunyi. 


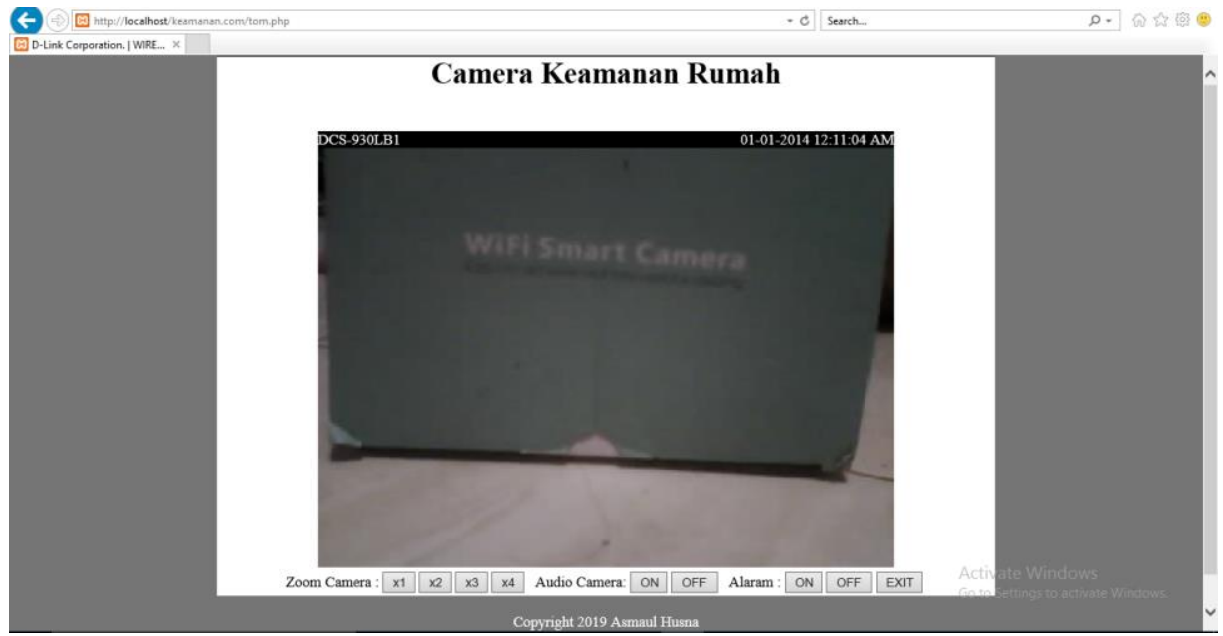

Gambar 7. Halaman aplikasi controlling streaming camera dan alarm Sumber: Gambar pribadi

\section{Kesimpulan}

Kesimpulan yang dapat diambil berdasarkan hasil pengujian adalah penggunaan Arduino uno dapat mengendalikan alat sistem kerja dan penambahan ethernet shield membantu menghubungkan alat ke PC melalui koneksi jaringan. Penambahan kamera IP pada sistem dapat mengetahui siapa saja yang masuk kedalam ruangan. Sedangkan penggunaan sensor ultrasonik bekerja mendeteksi hambatan yang mendekat lalu mengirimkan data ke Arduino, kemudian Arduino memproses data menjadi panggilan telepon dan membunyikan alarm. Pada penelitian ini penulis menggunakan perangkat jaringan lokal, yang membuat jarak akses masih terbatas. Penelitian berikutnya dapat dikembangkan sistem keamanan dengan memanfaatkan berbagai teknologi internet of things (IoT).

\section{Daftar Pustaka}

[1] Mallu S, "Pendeteksian gerakan menggunakan internet protocol camera berbasis web", Jurnal Ilmiah Teknologi Informasi Terapan, vol. 1, No. 3, 2015.

[2] Satria D, Yana S, Munadi, dan Syahreza S, Sistem peringatan dini banjir berbasis SMS gateway dan mikrokontroler arduino uno, Seminar Nasional II USM 2017, Vol. 1, 78-82, 2017.

[3] Hafiidh As Syahidulhaq, Hafiddudin, ST., MT., Suci Aulia, ST., MT, "Implementasi alarm camera IP berbasis passive infrared receiver (Pir) sensor dan SMS gateway, "Jurnal Elektro dan Telekomunikasi Terapan, Vol 3 No 2: JETT, 2016.

[4] Steven J S, Dringhuzen J. Mamahit, S. R. U. S, "Trainer periferal antarmuka berbasis mikrokontroler arduino uno," E-Journal Teknik Elektro dan Komputer, 5(3), 13-23, 2016.

[5] Syahwil dan Muhammad, Panduan Mudah Simulasi dan Praktek Mikrokontroler Arduino, Penerbit Andi, Yogyakarta, 2013.

[6] Dedi satria, Yanti Y, dan Maulinda, "Rancang bangun sistem penjadwalan bel sekolah berbasis arduino Uno dengan antarmuka berbasis web menggunakan ethernet web server, "Jurnal Serambi Engineering, Vol. II, no. 3, 2017.

[7] Mochtiarsa Y dan Supriadi B, "Rancangan kendali lampu menggunakan mikrokontroller ATMega328 berbasis sensor getar" Jurnal Informatika SIMANTIK, 1(1), 40-44, 2016.

[8] Apriansyah A, Ilhamsyah I dan Rismawan T, "Prototype Kunci Otomatis pada Pintu Berdasarkan Suara Pengguna Menggunakan Metode KNN (K-Nearest Neighbor), "Jurnal Coding, 4(1), 2016.

[9] Soleh dan Susilo A, "Desain dan implementasi smart home system pengendali lampu rumah berbasis arduino mega", Seminar Riset Teknologi Informasi (SRITI), 1, 99-106, 2016.

[10] Safwan, Zulfikar dan Zulhelmi, "Desain sistem keamanan rumah melalui penyalaan peralatan listrik berdasarkan kebiasaan pemilik rumah", KITEKTRO: Jurnal Online Teknik Elektro, 1(3), 7 14, 2016.

[11] Satria D \& Ahmadian H, "Designing home security monitoring system based interne of things (IoT) model, ” Jurnal Serambi Engineering, Vol. III, No. 1, 255-261, 2018

[12] Putra, Samuel Mahatma., Handoko., Mandasari, Rika., Bestari, Bimo Pramana, Analisis dan Perancangan Aplikasi Monitoring IP Camera Menggunakan Protokol HTTP pada Mobile Phone, Yogyakarta : SNATI 2010. 
[13] Mishra, S., Mishra, P., Chaudhary, N. K., dan Asthana, P. A Novel, "Comprehensive method for real time video motion detection surveillance," International Journal of Scientific dan Engineering, Research Volume 2, Issue, 2011

[14] Sumajouw D. F, Najoan M. E. I dan Sompie S. R. U. A, "Perancangan sistem keamanan rumah tinggal terkendali jarak jauh " E-Journal Teknik Elektro dan Komputer,1(1), 44-53, 2015.

[15] Agussalim, R., Adnan, dan Muhammad Niswar, "Monitoring cairan infus berdasarkan indikator kondisi, ” Jurnal Ilmiah ILKOM, 8(Desember), 145-152, 2016.

[16] R. R. Polii., "Analisa dan perancangan sistem informasi desa berbasis web model governmenttocitizen," J. Tek. Inform, Univ. Sam Ratulangi, vol. 12, no. 1, 2017. 